\title{
Factors generating stress in nursing students
}

\author{
Hayate Koubri ${ }^{1,},{ }^{*}$, Hinde Hami ${ }^{3}$, Sanou Khô Coulibaly ${ }^{1}$, Abdelmajid Soulaymani ${ }^{3}$, Nazih El Kouartey ${ }^{4}$, and Mohamed \\ Boulgana $^{5}$ \\ ${ }^{1}$ Faculty of Medicine and Odonto-Stomatology, University of Sciences, Techniques and Technologies, Bamako, Mali \\ ${ }^{2}$ Directorate of Population, Ministry of Health, Rabat, Morocco \\ ${ }^{3}$ Laboratory of Biology and Health, Faculty of Science, Ibn Tofail University, Kenitra, Morocco \\ ${ }^{4}$ National Agency for Health Insurance (ANAM), Rabat, Morocco \\ ${ }^{5}$ Service of Basic Training, Ministry of Health, Rabat, Morocco
}

\begin{abstract}
This study aims to explore the perceived stressors among students at the Higher Institute of Nursing professions and Health Techniques (ISPITS) in Rabat, and the coping strategies used. This is a descriptive study, based on the documentary analysis and the interviews, conducted, in 2009, among 500 students from all training courses and 18 administrative and pedagogical managers. Institutional factors $(78.8 \%)$ are clearly causes that generate students' stress in relation to personal and environmental factors. Students manage the stress, generated by all factors, adopting emotional, behavioral and cognitive attitudes. The majority of students engage in isolation and loneliness. The interventions of the sections coordinators towards stressed students take the form of listening and psycho-emotional support that they provide to them. Stress among undergraduate students at ISPITS Rabat is a reality. The establishment of a listening team for students, the improvement of learning conditions, good planning and organization of studies, and the dissemination of information and prevention programs to students and teachers are essential measures to deal with student stress. Stress management interventions should be offered to students at the beginning of their training in order to reduce the negative impact of stress and exhaustion on these students.
\end{abstract}

Keywords: Stress; Nursing students; Coping; Morocco

\section{Introduction}

The complex and accelerated development of our societies requires a permanent effort, which is a source of stress [1], which is considered a cosmopolitan scourge with serious consequences at the individual, organizational and social levels. In colleges, training centers and universities, students are no exception to this problem. As a result, they are exposed to this phenomenon and to exhaustion during their professional training $[2,3]$. They often face multiple constraints in their relentless struggle against the burden of studies; in addition to the physical constraints to which they may be subjected as a result of their extensive studies, students also experience increasing mental constraints throughout their training. But they are not alone on the tough path of knowledge: the conditions of the environment in which they live, their social environment constituted by peer groups and their families, are for them so many social supports or potential stressors [3].

As a result, too much stress can have adverse health effects, and promote the development of many diseases, such as heart disease, hypertension, stroke, depression and sleep disorders. In a research held in Scotland, Fischer (1994) showed that the transition to university manifests itself in anxiety, somatic disorders, depression and obsessive-like symptoms in about a third of students who have left the family home.

In Morocco, nursing students at Rabat's ISPITS do not escape this phenomenon because student life brings, on a daily basis, its impressive share of stressful situations. Their transition from secondary schools to ISPITS represents a new and sometimes difficult stage for some of them. They may face certain pedagogical, personal or environmental difficulties. They experience difficulties linked to different teaching approaches characterized by the alternation between theoretical courses and practical trainings. As a result, they perceive 
learning difficulties and social or socio-emotional problems, and have more discreet syndromes that are rarely the subject of medical consultations. These above factors can generate stress that has serious consequences for their health status and the progress of their studies. These findings therefore fully justify the scientific legitimacy of conducting a study on stressors among students. There is little data on the student nursing population and there is no predictive research on student nurses' health at Rabat's ISPITS, although it is common to hear about students' stress in general.

With this in mind, this study has set itself the objective of exploring and describing the factors that generate stress in nursing students. It is of top importance in our context given the close link between the problem studied and the state of physical, mental and social health of this category of students. Thus, proposals for action with regard to certain stressors of an organizational, environmental and personal nature, at Rabat's ISPITS, will contribute to the improvement of the learning environment among nursing students.

\section{Methods}

This descriptive study took place over 5 months (February - June 2009), at Rabat's ISPITS which has a national vocation and receives students from different regions of Morocco, as well as foreign national students. The study is based on the literature review, a questionnaire composed of 7 groups of questions, administered to 500 students from all training sections, structured and semi-structured interviews conducted with 18 administrative and pedagogical officials. The topics discussed during the interviews were the assessment of the phenomenon of stress at Rabat's ISPITS, the factors generating stress among undergraduate students, the actions implemented by the interviewees to act on these stressors, and the suggestions of the interviewees to prevent and control the phenomenon of stress among students.

The choice of the population is made according to a simple stratified random sampling, proportional to the number of students $(1,384)$. It consisted initially in considering the students of each stream (15 streams) as a homogeneous subgroup called "stratum"; then, in a second step, stratification was carried out by level of education. In a third step, stratification by gender was carried out. Finally, students in each gender group were randomly selected to form the final sample of the study composed of 500 students from Rabat's ISPITS. The analysis of the detailed results of the survey was carried out using CSPro and SPSS software respectively. For data relating to semi-structured interviews, we used essentially a thematic analysis of the content.

\section{Results}

500 questionnaires were distributed to students in all training streams; 490 were collected, representing a $98 \%$ response rate. The surveyed students have various characteristics. Most are quite young (75\% of students are under the age of 23$) .69 \%$ of students are female and
$83.1 \%$ of students live outside the city of Rabat. $73.1 \%$ do not live with their parents, of whom $19 \%$ live in a personal home. Indeed, these students experience seriously, if not very severely, the detachment from their parents.

In this sense, $28.8 \%$ of the surveyed students said that the distance from their parents is a stress factor for them. Added to this situation is the influence of socioeconomic conditions (the non-granting of scholarships for $54.3 \%$, and the absence of financial assistance from their families). This could be a cause of stress for some students, knowing that those in the first year cannot benefit from the residency at the boarding school level. As a result, students are obliged to bear the costs of accommodation.

The results of the interviews with the coordinators, the ISPITS Director, the Director of studies and the doctor in charge of the medical and social center revealed a range of problems experienced by the students, which generate stress for them. Indeed, socio-economic and emotional problems (distance from the family, difficulties in adapting, etc.), problems relating to learning and problems linked to institutional factors are causes that generate stress among students. Of course, these problems will have an impact on the students' health.

This study confirmed that Rabat's ISPITS students do not escape the phenomenon of stress. As a result, the survey found that $79.2 \%$ of students experienced at least an episode of stress in the last 12 months preceding the survey. Girls are more stressed than boys $(71.9 \%$ versus $28.1 \%$ ). This stress increases among second-year students (37.4\%) and the third year (37.1\%).

On the other hand, this study showed that stress is more marked among students in the "versatile nursing" training stream $(28.6 \%)$.

Fig. 1. Students' distribution by study's level and stress experience, or not, during the last 12 months before the survey

60

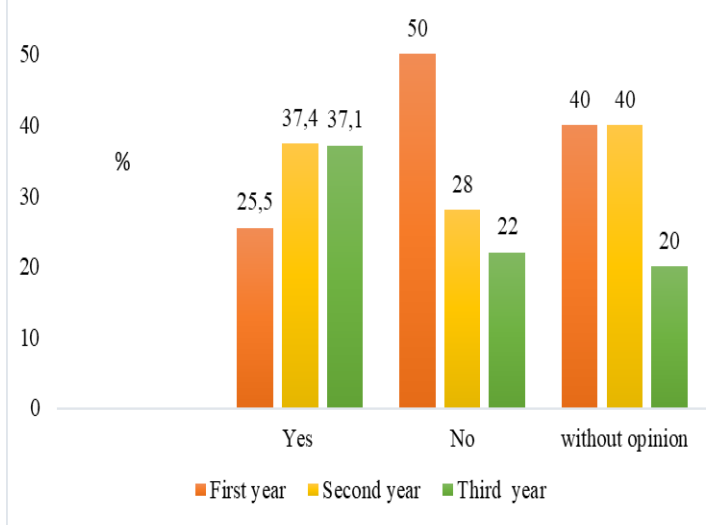

As a result, fatigue, nervousness and sleep disturbances are the signs of stress most evoked by students. Among the surveyed students, $73 \%$ experienced a period of more than 15 days during which they had at least three signs of stress (sleep disturbances, nervousness, irritability, loss of confidence, fatigue, headache migraine and anxiety), of which $52.2 \%$ experienced the sign of fatigue, followed by nervousness in $39.6 \%$. 
In addition, the study showed that stress is more frequent during the last quarter of the academic year: $65.9 \%$, compared to $10.6 \%$ in the first quarter.

This state of stress among students is triggered by several factors. In this sense, institutional factors (evaluations and exams, internships, program overload...) with a proportion of $78.8 \%$ are the stressors most reported by students in the last 12 months preceding the survey. Assessments and exams are the first factor (36.9\%) followed by program overload $(24.2 \%)$. Thirdly, there is the internship, with management problems, staff relations, the lack or absence of learning opportunities due to congestion at the internship sites. The last stressor among students is the "graduation project" or "thesis" with a proportion of $1.1 \%$. This factor is raised only among third-year students.

In addition, personal factors (family problems, fear of the future, health status / depression, etc.) come second, with a proportion of $12.4 \%$ reported by students.

Fig. 2. Factors generating stress among students in the last 12 months prior to the survey

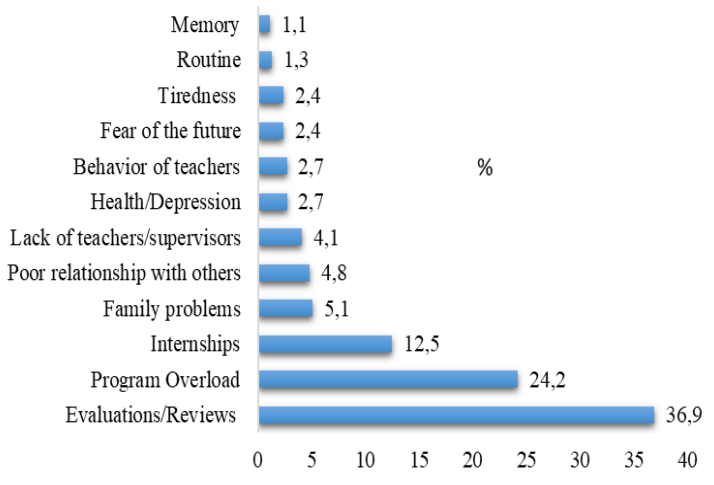

Faced with these factors, students manage their stress through different emotional, cognitive or behavioral attitudes and attempts, taking into account their personal and social resources. As a result, $26.1 \%$ of students are isolated when they are stressed, which can also accentuate their stress level.

Fig. 3. Stress management strategies adopted by students

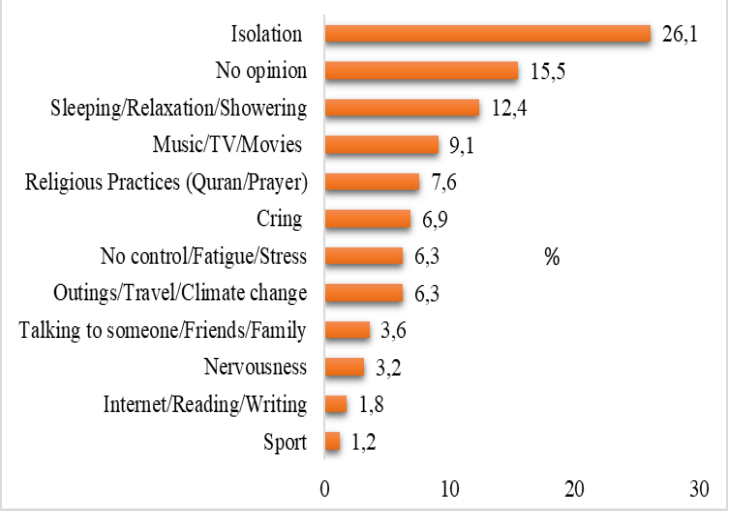

All these stressors, with their serious consequences, could justify the establishment of a strategy for the prevention and management of stress.

\section{Discussion}

The proportions of the varieties of stressors among students show that there is a clear influence of institutional factors.

Analysis of the results shows a strong incrimination of personal factors in triggering stress in students. Female students are generally more vulnerable than their male peers $(71.9 \%$ versus $28.1 \%)$.

Among the students surveyed, $19.4 \%$ are disappointed with their choice of studies. A proportion of $42 \%$ of students do not have a clear vision of the future mapped out by their choice of studies. These findings were confirmed by interviews with the coordinators of 15 sections, the Director of Studies and the ISPITS Director. This may mean that some respondents are stressed because of personal plans' lack.

In addition, $46.9 \%$ among the surveyed students raised that the wrong choice of studies is a stress factor for them. Also, the present study has shown that some students have had a lack of information and orientation: $50 \%$ have not been sufficiently informed to choose their field of study at ISPITS. This corroborates what was provided by a study carried out in 2007 by the National Union of Regional Student Mutuals (USEM) on students' health. According to the USEM study, more than $50 \%$ of students feel that they have not been sufficiently informed when choosing their orientation.

In addition, $24.9 \%$ of students have chosen their course coincidentally and may, as a result, have difficulty adapting to the ISPITS level, and therefore experience a stressful situation. This is confirmed by the fact that among the students surveyed, $71.7 \%$ say that the lack or absence of motivation is a source of stress for them.

On the other hand, uncertainty about the future is also a stress-generating factor for students. According to the results of this study, uncertainty about the future is a stressor for $62 \%$ of students. These results support what was reported by Montgomery and Rupp (2005).

However, the student survey revealed that the socioeconomic environment of students is a determinant of stress in their country. These results support what was reported by Boujut and Bruchon-Schweitzer (2003) [4].

In another sense, the experience presented underlines the importance of other personal factors that are clearly perceived as stressors. Indeed, $64.7 \%$ of the surveyed students said that distance from their family is, for them, a stressor. Life outside the moral, financial and domestic protection of parents is unfavorable to the mental and temporal investment required for higher education. From this point of view, the type of student accommodation (alone, as a couple, with the parents) is an interesting indicator of the possibility of focusing on purely academic occupations [5]. According to the results of this study, only $26.9 \%$ of students live with their parents.

Indeed, when the social support of the family is absent, the stress increases. In this sense, students without the 
support of their institution, their entourage or their peers, are the most exposed to stress. According to this study, $28.2 \%$ of students do not receive help from those around them, and $59.4 \%$ sometimes, or even often, feel the need to be helped by teachers outside school hours. As a result, social support plays a protective role. It can be directed with the aim of valuing the student, increasing selfesteem, contributing to the realization of school activities and reducing stress [6-8].

In this case, it seems that an effort is needed to facilitate relations between students and with teachers and ISPITS officials, which could be used by the student if necessary. In another sense, the lack of social support and the difficulty of adapting to higher education lead to a loss of confidence among students, with $49.8 \%$ of them saying that they lacked, or lost, confidence in themselves and their abilities [6].

Moreover, the results of the questionnaires reveal that the social environment of students is decisive in triggering stress in them. Indeed, $38.5 \%$ of students are stressed by family problems and arguments with relatives. Some coordinators have also confirmed this factor. The extent of social stress in a population depends on variables such as integration status, role conflict, frustration, achievement of goals and lack of autonomy. This type of factor is influenced by other causes such as diet, climate, social class, type of housing and remoteness, which vary by culture and geography [9-11].

In addition, the surveyed coordinators revealed that some students are predisposed to stress because they have anxious personality traits. This finding is supported by the results of the questionnaires. The irritation they show, their high level of nervousness and their need for competition make them feel constantly pushed and under pressure. Several studies have highlighted the relationship between personality traits and stress [12].

In another sense, $50.9 \%$ of students were stressed because of health problems that can manifest themselves in fatigue, sleep and eating disorders. The huge majority of students' report being tired during the school period and thus support what was reported by the coordinators during the interviews [13].

By way of summary, the student's personal factors, namely: (a) personality type, (b) financial difficulties, (c) lack of confidence or self-esteem, (d) uncertainty about the future, (e) health status, and (f) sociodemographic variables, are all determinants of nursing students' stress. In addition, factors related to the institution and its organization have their part in triggering stress among students. In this respect, this study raised the difficulties of integration and the vulnerability of first-year students, who are suddenly cut off from their family environment and discover a new educational environment. The difficulty of adapting to higher education requirements, and those of vocational training, leads to a loss of students' self-confidence and abilities, and increases their feelings of loneliness. The first year of studies corresponds to a particular moment in their life cycle, and this situation generates a state of stress that students sometimes do not know how to manage [6, 14]. This context can also promote the appearance or worsening of depressive symptoms, as well as the adoption of risky behaviors and comportments. Researchers had found that during the first year of medical school, students' selfesteem decreased and depression increased [15]. Thus, low self-esteem could maintain or reinforce the negative affects already present without necessarily going through dysfunctional coping strategies such as drinking, smoking or consuming narcotics.

In another sense, analysis of interviews with teachers revealed that institutional factors are the main ones that trigger stress. These results confirm those of the American study carried out among 181 students in the first year of medical school, which revealed that the main problems identified, and which generate stress among students, are of an academic nature [13, 15].

As for environmental factors, the frequency of major life events has an impact on the triggering of stress and suicidal ideation in students. Indeed, the student population faces many daily hassles. This has consequences for their reactions to stress and for their health [16]. These findings have been proven by some coordinators who have stated that some stressed students behave aggressively with their colleagues or with teachers.

On the other hand, some students have learning and assimilation problems caused by the nature of the modules taught. As a result of these difficulties, the student is likely to develop a feeling of incompetence that can seriously affect his motivation and modify his objectives of pursuing studies. Thus, to reduce the impact of these difficulties and give the student a chance of survival in his study project, it is important to give a place to peers, who represent effective agents in terms of listening, support and encouragement [17].

This study as well showed that feelings of loneliness also generate stress. Indeed, these students require the social support of their teachers and colleagues. This support can play a key role in restoring a student's self-esteem, confidence and belief in personal abilities, which are essential components of further education. In the absence of this relationship, the student is exposed to stress. These results support those of the USEM study.

At the end of results' discussion, the cross-analysis of the outcomes obtained by the interviews shows that all the participants are aware of the stress extent at Rabat's ISPITS. They have all proved its existence and its consequences for the student and the institution. As a result, they intervene at certain times to support students in difficulty. Nevertheless, some coordinators have stated that they cannot ensure the listening and accompaniment of students in difficulty in parallel with their teaching activities. Indeed, they suggested the implementation of preventive and curative stress interventions.

As for students' behavior towards stress, they adopt different attitudes to manage it. These attitudes differ from one student to another. In this sense, everyone preferentially mobilizes some strategies rather than others facing the variety of aversive situations of life, and taking into account their personal and social resources.

\section{Conclusion}


Stress is a complex phenomenon and an important dimension to be taken into account in promoting young people's health, especially students. The implementation of measures to remedy this problem requires knowledge of its triggering factors, and its treatment must be undertaken in a comprehensive approach, far from any linear methodology, in order to limit all its consequences on the student and on the institution. Each student reacts specifically to stressful situations, and what beats one person can be a source of motivation for another. Indeed, information on stress will make it possible to understand the hidden workings of this phenomenon and will offer everyone the opportunity to identify their potential "stressors" in order to reduce their impact, cohabit with, or neutralize them.

The students' stress at Rabat's ISPITS seems multifactorial, although its main triggers seem to be mainly related to the student's personal factors, institutional factors and environmental factors. These different factors mentioned by the students who participated in this exploratory study and by the results of the interviews conducted with some resource persons show the need to have a broad approach in order to identify, together, the factors present in situations likely to cause stress.

From a primary prevention perspective, it would be wise to identify vulnerable students upstream, in order to try to reduce their risk of developing certain symptoms of stress. This approach assumes that students have more control over their own health. This would require accentuating health promotion actions and reinforcing the idea of better preparing students to manage stressful situations, teaching them functional adaptation techniques and problemfocused strategies, as an integral part of their studies. Students, who use emotion-centered strategies, and not problem-centered strategies, would avoid the problem, rather than attempt to solve it. This strategy would be dysfunctional, and associated with the development of depressive symptoms insofar as it does not make it possible to eliminate the stressful situation, which persists.

In addition to primary prevention, early secondary prevention requires enhanced screening to prevent worsening of depressive symptoms and progression to proven pathologies. All prevention activities could be carried out by the listening and support team suggested by the study, in consultation with the ISPITS medico-social center and other partners.

\section{Acknowledgements}

The authors would like to thank the Director of the Higher Institute of Nursing Professions and Health Techniques / Rabat Morocco, the Director of Studies, the teachers of Rabat's ISPITS and its administrative managers. They also thank the managers and executives of the Training Division / Human Resources Department of the Ministry of Health of Morocco, the managers of the library of the National School of Public Health of Morocco and the managers of the National Documentation Center of Morocco.

They also thank all the people, who by their commitment, contributed to the realization of this Study.

\section{References}

1. J. Rivolier, L'homme stressé, Ed. Presses Universitaires de France, 306p. (1989)

2. D.W. Chan, Hardiness and its role in the stress-burnout relationship among prospective Chinese teachers in Hong Kong (2003)

3. C. Montgomery, A.A. Rupp, Canadian Journal of Education, 28 (3), 458-486 (2005)

4. E. Boujut, M. Bruchon-Schweitzer, Le stress et la santé chez les étudiants de première année. Une approche transactionnelle en psychologie de la santé (DEA Thesis, 2003)

5. C. Grignon, L. Gruel, Revue Française de Pédagogie 136, 184-186 (2001)

6. E. Boujut, Facteurs prédisant le développement de symptômes dépressifs, de symptômes somatiques, de troubles des conduites alimentaires et de l'échec académique chez des étudiants de première année (Thesis, 2007)

7. E. Boujut, M. Bruchon-Schweitzer, Le stress et la santé chez les étudiants de première année. Une approche transactionnelle en psychologie de la santé. Université de Bordeaux (2003)

8. I. Brember, M. Brown, S. Ralph, Westminster Studies in Education, 25 (2), 175-186 (2002)

9. C. Grignon. Les étudiants en difficulté, pauvreté et précarité (Report, 2000)

10. C. Grignon, L. Gruel, La vie étudiante (1999)

11. C. Grigon, L. Gruel, B. Bensoussan, Les conditions de vie des étudiants (2000)

12. S.C. Kobassa, J. Psychosom. Res., 29 (5), 525-533 (1985)

13. D. Hallet, F. Vanderstichelen, Education Santé, 217, 2-6 (2006)

14. J.J. Arnett, Adolescence and Emerging Adulthood: A cultural approach, Ed. NJ: Prentice-Hall (2004)

15. T.M. Wolf, T.K. Almen, J.M Faucett, H.M., Randall, Med. Educ., 25 (3), 174-181 (1991)

16. J.D. Moulds, Psychology in the Schools, 40 (4), 391402 (2003)

17. L. Montminy, N. Duval, Tous pour un. Les relations paires étudiant et professeur étudiant Facteurs de la réussite universitaire (2001) 